this book from either side of the Atlantic Ocean is remarkable as the book has the feel of authors working in adjacent rooms!

There are five distinct sections to the book: (1) Basis and Principles. (2) Minimal Clearance Haptic Contact Lenses. (3) Corneal Contact Lenses. (4) Flexible Lenses. (5) Special Contact Lenses. The first section on principles covers the range of simple corneal anatomy and physiology with helpful detail concerning the materials and manufacture of contact lenses. Comprehensive and well written second, third and fourth sections deal exclusively with all the different types of contact lenses. Equal emphasis and a fair evaluation of the pros and cons of the different types of contact lenses is made. The fifth and final section deals with contact lenses used in special situations, both diagnostic and therapeutic. This section is a useful reminder that contact lenses are not exclusively used to correct refractive errors. Certain special lenses, for example those used in gonioscopy and retinal electro-diagnostic tests are mentioned, but probably more for completeness than for much detailed information. Contact lens fitting in certain pathological conditions is mentioned but probably the authors' particular experience in this specialized field may not be so complete as the rest of their expertise as it is significantly superficial in descriptions of some pathological conditions.

The illustrations throughout the book are excellent, the quality of the paper, layout and print equally of a high standard. There are useful appendices of conversion tables for contact lens work and a Colour Plate Section of good colour photographs of numerous situations of contact lenses in situ on the cornea which provide a rapid and ready reference.

All in all, an excellent book written by experienced, practical contact lens practitioners for all those concerned with contact lens fitting. Both ophthalmologists and optometrists will learn much from the authors' sensible approach and Contact Lens Correction will provide a ready source of reference for some years to come.

\section{Diabetes Mellitus. Clinical and Metabolic}

By W. P. U. JACKson and A. I. Vinik. Pp. 265, hard cover, illustrated. Cape Town: Juta \& Co., 1977. R13.50.

Probably no single ailment has attracted more attention than diabetes mellitus and there are many reasons for this. It is a widespread and common disorder, its aetiology is ill understood and the treatment demands understanding and skill. Diabetes can affect every system in the body and, in broad terms, the longer the diabetic state has existed, the greater the likelihood of degenerative changes in the eyes, the kidneys, the nervous system and the vasculature. Much research has teen directed to these problems and attitudes are changing.

Hence there is a constant need for up-to-date text books, some directed towards the pathologist, some to the biochemist and some to the clinician. This particular text book is intended for the postgraduate student and for the general physician. It contains an adequate background of biochemistry, pathology and genetics and, because the clinical advice is based on the authors' wide experience in the Groote Schurr Hospital in Cape Town, it provides good practical advice on management, although often idiosyncratic. Information is somewhat lacking on the role of fibre in the diet, the newer insulins and the place of photocoagulation in the treatment of retinopathy. The style of writing is informal and frequently otiose with phrases such as 'How wise of Mother Nature' or 'The skin is the wrapping for all our organs'. With these minor reservations, the book can be recommended as stimulating and informative.
Fundamentals of Obstetrics and Gynaecology. Volume 1. Obstetrics

By DeRek Llewellyn-Jones. Pp. 471, soft cover and hard cover, illustrated. London: Faber \& Faber, 1977. Hard Cover $£ 12.00$. Soft Cover $£ 9.75$.

What a pleasure it is to welcome the second edition of this book. The first edition appeared in 1969 and one was immediately attracted by the layout and the clarity of thought of the author. The book rapidly became, justifiably, a favourite with undergraduates.

The new edition retains the previous style and, apart from extensive revision, carries new sections on the active management of labour, epidural anaesthesia, ultrasonics, the 'at risk' fetus and fetal monitoring. The book carries the individual stamp of the author and will prove as popular with current students as the previous edition has already proved with their predecessors.

It cannot be recommended too highly.

\section{Genetic Counselling}

By Alan Carruth Stevenson and B. C. Clare Davison. Pp. 357, hard cover, illustrated. London: William Heinemann Medical Books Ltd, 1976. £5.50.

Counselling families with genetic problems is now a part of the every-day practice of many doctors, especially paediatricians. It is easy to give a prognosis when the condition is a simple autosomal, dominant recessive disorder, if one understands Mendel's principles. It is not so easy for disorders of polygenic inheritance or when a distant female relative of someone with a sex-linked recessive disorder wants an opinion on the chances of being a carrier. Where should one turn for information? This book, now in its second edition after only six years, will provide most of the answers and tello you where to go for even more detailed information.

Of the 24 chapters, 14 are devoted to conditions in varioussystems so that one can look up a rare disorder to find ou how it is inherited and the risk of having another child with the same problem. The book opens with a chapter on elementary genetics setting out the principles from which the rest flows. It then shows how to calculate simple risks and goes on to more complicated examples such as the risks of consanguinity. There is a chapter on chromosomes; the present reviewer was a little disappointed here not to find figures on the incidence of Down's syndrome at different ages of the mother-figures are given for the risk of having another child with the disorder but not for the first one. This leaves a gap when reading about antenatal diagnosis, since the authors give rather bald indications for amniocentesis. This subject is increasing in importance and therefore the section needs expanding. The short chapter on 'Our patients and their problems' is a very good idea but needs a little more discussion than three pages.

A good book for the every-day shelf, so that one can look up odd conditions or find out how to calculate risks. The reviewer thinks that the beginner in genetics should probably start with a simpler book and then move on to this one.

\section{Haemostasis. British Medical Bulletin}

(Vol. 33 No 3 September 1977)

Introduction by Professor R. G. Macfarlane. Soft cover, illustrated. London: The British Council, Medical Department, 1977. U.K. $£ 4.50$ Other countries $£ 5 . C 0$.

This number of the British Medical Bulletin is devoted to haemostasis and it maintains the high and authoritative standards of its predecessors.

The first four papers are largely devoted to platelets. Then follows a restatement of the coagulation process, as far as possible, in biochemical rather than in 'factor' terms. The 